\title{
The Archive and the Digital Age: Field Notes from the Pedagogical Front
}

\begin{abstract}
The digital environment in which the humanities are now firmly immersed has opened the door to innovative ways for students to interact with traditional formats such as archival and print material, and to develop a deep and personal understanding of topics and issues. Libraries, museums and archives are in the unique position of facilitating the creation of digital initiatives in the classroom by offering up their collections as "learning laboratories," and by sharing their expertise in technology, information, and digital literacy as well as data management. Through active collaboration with course instructors, they can build bridges between their collections and the digital skills students need in order to embrace the new learning paradigm and to help lead them into the future. This paper outlines an archival-digital pilot launched in 2015 at the University of Ottawa, Canada. It situates the project in its historical context; details its early and subsequent iterations; and surveys the assumptions, challenges, surprises, and pleasures of introducing students to archival sources and to acquiring digital skills.
\end{abstract}

Keywords: Digital Humanities, Hamlet, Shakespeare reception, teaching Shakespeare, Shakespeare in Canada.

\section{Shakespeare 400}

In the Fall of 2015, the University of Ottawa, situated in the nation's capital, was preparing for Shakespeare400, a nearly four-month celebration of Shakespeare's afterlife that was to begin in January 2016, and which encompassed scholarly, pedagogical, creative, and community outreach activities. Ranging from the serious to the whimsical, the celebrations involved extensive collaboration among the faculty, staff, and students of the University's Faculty of Arts, Social Sciences, Law, and Medicine. Forty separate events, many open to the public, were held at the University, among them, an opening gala, two concerts, lunchtime talks (on topics as various as dreams, the plague, and translation), an art

* University of Ottawa, Canada. 
exhibition, new musical works created by young composers, a sonnet competition, film festival, scholarly conference, and a reading of Hamlet in thirty-seven languages spoken by faculty and students. The diverse program was designed not only to honour Shakespeare and to highlight his rich and varied afterlife, but also to have fun, create a community spirit, and to inspire an engagement with Shakespeare's works on diverse levels and through various media. Nearly one thousand participants, presenters, performers, artists, collaborators, and volunteers took part in the project. ${ }^{1}$

The unusual circumstances of that anniversary celebration also seemed prime for experimentation in the classroom. Canada's oldest bilingual (FrenchEnglish) university (established 1848), the University of Ottawa is built on unceded territory belonging to the Algonquians. Its bilingual and bi-cultural traditions, enshrined in its mission statement, both enrich and foreground the problematic position of Shakespeare in a multicultural and multilingual settlerinvader nation. For First Nations, Shakespeare continues to remain either a peak to be scaled or, more frequently (especially through adaptation), to be upended. In the province of Quebec, Shakespeare was historically (and pointedly) neither part of the school curriculum nor part of the repertoire of local professional acting companies. Comfort with Shakespeare was only achieved in the latter part of the twentieth century. ${ }^{2}$ How, then, to analyse the relationship between the global and the local? To examine the complexity of Shakespeare's reception in Canada, one which is deeply ensconced in the political and cultural history of this country? How to make students aware of the way in which their identities have been shaped by such processes and clashes?

Pedagogical challenges did not stop here. For many, if not most, Canadian students today, Shakespeare is a classic in Balz Engler's sense of that term: that is, a writer whose works have left the page, entering daily parlance through quotations, reference to characters, and stories (217-316). Although thus somewhat familiar, Shakespeare has nonetheless become more alien to students today than he was just a decade or two ago. He is separated from their daily reality by language; by time; by history; and by geography. The current "tweet"

${ }^{1}$ Over four years in the making, the whole project was led and co-ordinated by Irena Makaryk, Department of English, with the able and energetic assistance of Kathryn Prince, Department of Theatre. Individual events involved other faculty members and volunteers. See the Shakespeare400 website for details: http://artsites.uottawa.ca/ shakespeare-celebrations/en/media/

2 For a historical overview of Shakespeare in Canada see Irena R. Makaryk, "Introduction: Shakespeare in Canada: 'a world elsewhere'” (3-41). For Shakespeare in Quebec, see Annie Brisset, "Shakespeare, A Late Bloomer on the Quebec Stage" (127-56). On First Nations and Shakespeare, see Sarah Mackenzie, "Performing 'Indigenous Shakespeare' in Canada: The Tempest and The Death of a Chief," in Makaryk and Prince (111-25). 
generation often finds Shakespeare's language remote, dense, difficult, and verbose. ${ }^{3}$ For most of them, British history is - to borrow Viola's words to Duke Orsino-“a blank.” The Ontario Ministry of Education's single compulsory requirement for the subject of History at the secondary-school level is one credit, to be taken in Canadian History in Grade 10. Thus, not only British but also world history is, regrettably, terra incognita. To follow up that metaphor, the only compulsory Geography requirement is Canadian geography. Few Canadian students have travelled to England or have even closely examined a map of it and, as a consequence, the reverberative place names of, say, Shakespeare's history plays, mean little or nothing to them. Lastly, Shakespeare's works are no longer a required element of the secondary school education curriculum, although a number of English teachers still choose to include one of his plays in their syllabi. ${ }^{4}$ Whatever we may think of the decisions taken nearly fifteen years ago by the Canadian ministerial powers, the result is to create significant challenges for those of us teaching Shakespeare at the university level.

In the province of Ontario at the University of Ottawa, undergraduate Shakespeare courses are pegged at the third-year level and are divided into two separate sections, Elizabethan and Jacobean Shakespeare, each with enrolment capped at 45 students. Typically, students are required to submit three assignments per academic session, including a final essay of 10 to 12 pages.

With the enthusiastic support of the librarians and media specialistsAnn Hemingway, Nancy Lemay, and Roxanne Lafleur-the resident Shakespearean, Irena Makaryk, was encouraged to introduce a pilot archivaldigital component into her undergraduate Shakespeare course. The project entailed Makaryk’s setting aside her "initiate fears": fears of technology itself; of students taking on these projects just to avoid the work of writing and researching a formal research essay; and of letting go of total control over her course. Only twenty-one students were permitted to take part in this pilot. Its unexpected and overwhelming success and the satisfaction derived from it by students, librarians, and the instructor, led to continuing the project over the next four years; it also resulted in wider, positive consequences as well, as will be seen below.

3 For the first time in nearly four decades of teaching, Irena Makaryk encountered undergraduates who are reading modernized versions of the plays alongside their regular texts. She has also encountered graduate students coming to Ottawa from other universities who have never studied Shakespeare before. These students have specifically mentioned that they had avoided Shakespeare because were "afraid" to tackle his works.

4 On Shakespeare in the Canadian educational curriculum see Dana M. Colarusso, "Rhyme and Reason: Shakespeare's Exceptional Status and Role in Canadian Education,” in Makaryk and Prince (215-40). 


\section{Pedagogical Trends and Assumptions}

In the past decade or so, three areas of pedagogical emphasis have emerged in Canada: 1) an emphasis on the importance of an early introduction to primary research; 2) a focus on developing digital humanities literacy; and 3) experiential learning as a replacement for traditional modes of discovery, research, and writing. Two generally-held views seem to underpin these relatively newlypromoted trends: that the current generation of undergraduates is more comfortable with visual material than with print; and that students are savvy in their use of the Internet and therefore would not only benefit from, but would also thrive, when working on digital humanities projects. Concurrently with these developing trends, the field of Information Studies has been undergoing considerable upheaval. With the rapidly expanding intersections among technology, pedagogy, learning, and the humanities, much debate has erupted concerning the benefits and drawbacks of the convergence of libraries, museums, and archives. ${ }^{5}$ The pilot project was intended to respond to these new directions and debates.

\section{Project Overview. Shakespeare in Canada: Exploring Cultural History through Digital Humanities}

The overarching goal of the pilot project was to have students come to understand how deeply — and often problematically—Shakespeare is embedded in the cultural fabric of Canada. This embeddedness includes Shakespeare's presence in various media and reaches back into the pre-Confederation period (before 1867, when Canada was founded). Undertaken in lieu of a final research paper, the archival-digital project was an option made available to a limited group of students, supervision being one of the major constraints. Working in groups of three on specific themes, twenty-one students carried out primary research in Library and Archives Canada; our own institutional archives; and those of other major institutions (e.g. Canadian Broadcasting Corporation). For this first group, the general themes assigned were as follows:

5 See Robert VanderBerg, "Converging Libraries, Archives and Museums: overcoming distinctions, but for what gain?" (136-146). This was also the subject of a panel, "Convergence of LAMs (Libraries, Archives, and Museums)," at the Library Association of Canada Forum Conference, 2 June 2016. On the role of libraries in digital humanities pedagogy see the following two articles: Francesca Giannetti, "Against the Grain: Reading for the Challenges of Collaborative Digital Humanities Pedagogy" (257-269). Melanie Griffin and Tomaro I. Taylor explore best practices in "Shifting Expectations: Revisiting Core Concepts of Academic Librarianship in Undergraduate Classes with a Digital Humanities Focus” (452-466). 
1. Nineteenth-century political cartoons of Fathers of Confederation, depicted as Shakespearean characters, and featured in Canadian newspapers.

2. Canadian Broadcasting Corporation (CBC) radio adaptations of Shakespeare plays from the 1930s and early 1940s.

3. Television parodies of Shakespearean works from the 1950s and 1960s by the comedy team of John Wayne and Frank Shuster.

4. Theatre critics writing about the early years of the creation of The Stratford Festival (Canada): Nathan Cohen (writing throughout the 1950s and 1960s) and Urjo Kareda (writing in the 1970s and early 1980s).

5. Student Shakespeare productions at the University of Ottawa by the French and the English theatre guilds.

6. Selected professional Shakespeare productions at the National Arts Centre, Ottawa.

7. Selected productions at The Stratford Festival, Ontario.

In subsequent years, these themes were changed annually and included such topics as First Nations adaptations; francophone Shakespeare; and amateur theatre productions of Shakespeare.

In the first two years, students set off for the archives accompanied by the librarians. There, they examined fonds pre-ordered by the course instructor, sifted through boxes, and selected their assets (photos, programs, newspaper clippings, drawings, playbills, etc.). Later, they scanned, uploaded, and catalogued them. Narrowing down their topic, they shaped the material into a narrative arc; augmented their archival findings with published scholarly sources; and then created digital exhibits which, when completed, they presented in a public forum attended by an audience of peers, friends, and other faculty members and guests.

In the process of creating their projects, the undergraduate students were given the opportunity to hone research and communication skills, learn new technologies, and develop marketable digital literacy skills. Omeka, a free opensource content-management system, was selected as the best platform to host the exhibits for multiple groups of students since it offered enhanced functionality and a relatively easy learning curve. The University of Ottawa Morisset Library hosts multiple instances of this application and has the in-house expertise to provide ongoing technical support. Omeka also proved an excellent teaching tool for introducing students to the various components of database development and for demonstrating the importance of the rigorous cataloguing of metadata.

In first iteration of the project, the software Shared Shelf, now JSTOR Forum, was used to add and catalogue data. Shared Shelf provided students with a robust platform to upload images and files, input descriptive metadata for their assets, and publish their content to the Omeka portal. The data management application also allowed the team of librarians and media specialists to develop 
a detailed cataloguing scheme which was to serve a purpose beyond the classroom assignments. The data obtained by these undergraduates was augmented with documents and artefacts borrowed from the Stratford Festival Archives (Ontario) and from the Theatre Museum of Canada in order to form the basis of a physical and digital exhibition of Shakespeare in Canada which constituted part of the Shakespeare 400 festivities. Curated by three Information Studies graduate students, this exhibition was another collaborative endeavour creating new linkages; in this case, among undergraduates and graduates, library, archival, museum, theatre, and professorial staff. Highlights of the exhibition may be found here: http://216.48.92.16/omeka1/shakespeare400/. See "Featured Exhibit” at the bottom of the page.

In order to develop their exhibits, students used a variety of open source and free applications and employed high resolution scanners and cameras. They were given carte blanche to experiment with a variety of available plugins to build their exhibits, namely Tiki-Toki, Youtube and StoryMap JS. Many also customized their exhibits using a range of creative software including Photoshop to manipulate and enhance images: iMovie and Movie Maker to edit video footage; and GarageBand and Goldwave to add sound clips and music. The Library project team (Hemingway, Lafleur, Lemay) guided the students in the use of the equipment, plugins, and software, and directed them to the tools that would be best suited to their projects, all the while providing them with the technical support to embed their exhibits in Omeka.

The two best examples of this first group of undergraduate projects may be found here:

a. On the work of theatre critics Nathan Cohen and Urjo Kareda: https://s3. amazonaws.com/uploads.knightlab.com/storymapjs/d3f9d48d3a76c38aa06c2 6628705ee31/toronto-critic-map/index.html

b. On the comedy team of Wayne and Shuster and their parodies of Shakespeare: https://www.youtube.com/watch?v=UnEC6AbD8Ew\&feature=youtu.be

\section{Sharing the Classroom}

The pilot project was also conceived of as Community Service Learning (CSL), that is, as experiential learning since its raw data constituted a contribution to the Shakespeare 400 celebrations. CSL projects, which have proliferated at the University over the past decade, vary greatly in nature. Typically, they take up 30 hours of the student's time. Students are individually evaluated by a supervisor on a range of professional skills ${ }^{6}$ and, if the project is successfully

6 The students were evaluated according to a well-defined set of criteria: attendance and punctuality, ability to follow guidelines and instructions, interactions with people with whom they worked, desire to learn and improve and to integrate feedback, level of 
completed, they receive a special notation on their academic transcript. Upon submission of the final project, the student is required to submit a short paper reflecting on its challenges and opportunities. In this particular case, the students were evaluated by the course instructor after extensive discussions with the Library team. Following their public presentation, the student projects were posted on the web.

Participating in the pilot as an alternative to the traditional essay, students experienced a unique learning opportunity in which they themselves were knowledge creators, employing and analysing primary material. They were also part of a team. As in a professional workplace experience, they worked in close proximity with others: in this case, with archivists, librarians, and media specialists. Through the community service-learning model, they also acquired professional, transferable skills that could appear on their resumes. These included advanced research skills in the digital humanities; archival documentation skills (i.e., an achieved understanding of how archives work and how to work in archives; how to collect material, log information, correctly describe and evaluate it). Critical, analytic, and evaluative skills were honed through the decision-making process of selection and posting of material. Communications (written and oral) and team-building skills were also developed, since students were required to be in weekly contact with their librarian-mentors, as well as with the course instructor.

A number of students expressed enthusiastic interest in pursuing graduate studies in the domain of Information Studies, something they had never considered before. For some, the CSL component even resulted in immediate and tangible benefits. The students working on television parodies of Shakespeare were invited to speak about their archival findings on a daily radio program at our local CBC news station. A student from this same group later found a summer position with the City of Ottawa Archives because of the experience and skills she was able to demonstrate. One of the students in another group was hired for summer employment by a governmental agency as a concrete result of the project.

Library staff as well as students reaped significant benefits. Librarians rarely have the opportunity to accompany students through their academic arc of an entire semester. Normally, the only occasion in which librarians interact with students in the classroom is during the one-time research-skills workshop which they traditionally offer to undergraduates. In the course of the pilot project, librarians came to know all the students through their weekly, and sometimes daily, encounters. They provided timely and tailored instruction and support through the different stages of the project and developed a meaningful mentoring

initiative, successful completion of agreed upon responsibilities and benefit of service to organization. 
relationship with them. ${ }^{7}$ Embedding librarians and library specialists in the project also changed the students' perception of the library from a mere repository for books to a dynamic and responsive hub of resources, expertise, and services. After working together on this project, librarians also better understood the challenges professors face in the classroom.

\section{Surprises}

The pilot project brought many surprises for all. For the course instructor and library team, the first surprise was that those students who signed up for the archival-digital option were not savvy about the use of digital media nor were they skilled in thinking visually, despite the fact that they were constant users of the Internet. For the students who thought the project might be easier than writing an essay, the surprise was that most of the same requirements obtained: a thesis was needed; material had to be researched and winnowed, analysed, then edited to retain both a clear focus and a coherent narrative. Thus, the strongest projects emerged from the strongest, most disciplined, students.

Traditionally working alone on their essays, literature students found it challenging to adjust to working in groups. ${ }^{8}$ Especially novel was the experience of working with three sets of professionals: the instructor, librarians/archivists, and media specialists. The usual trials of working in groups-not everyone contributing equal weight to the project—was compounded by communication issues. Students carried over their informal and sometimes erratic style of communication from other digital platforms (e.g., Twitter) into emails directed to professional staff at museums, archives, and other institutions. They often forgot to copy each other on emails and thus, occasionally, work was duplicated by these inadvertently closed-off communication channels.

On the plus side, as the students happily explained at project's end, in the process of undertaking archival and digital work they were discovering themselves - that is, the formation of their Canadian identities through the prism of Shakespeare. They were also discovering their own blind spots: their preconceptions and biases. For example, working from their own limited experience with Shakespeare, one group of students presumed that parodic versions of Shakespeare from the 1950s (such as those by Wayne and Shuster) had been created in order to make Shakespeare "relatable" and "less threatening"

7 See the latest iteration: https://uottawa.libguides.com/shakespeare-cdn

8 In the last iteration (Winter 2019), two students strongly insisted on being the sole creators of their projects. Interestingly, these were not nearly as successful as the group undertakings. The idea of negotiating and sharing information with others, and working through the various elements seems to have been a key factor in the success of projects. 
to their audiences, since this is what they believed were today's theatrical, cinematic, and even pedagogic, goals. It did not occur to them until prompted to review earlier educational curricula that, in fact, parody was only possible because a good swath of television-viewing audiences already knew their Shakespeare and enjoyed seeing his works being "sent up."

Unquestionably the greatest surprise of all was the fact that each and every one of the students in the first group became enraptured by work in the archives, that is, by dealing with analogue rather than digital material. Their reflective papers commented on the excitement of sifting through boxes of documents, making discoveries, and feeling great pleasure by literally touching scraps of Canadian history. One example will suffice here. Throughout their concluding public presentation, the theatre critics group continually referred to the subjects of their study by their first names: Nathan and Urjo. When queried about this, they explained that, through the process of sorting through documents from the most mundane to the significant, they felt that they had come to personally know Nathan Cohen and Urjo Kareda. Canadian history and Shakespeare's role in Canadian cultural life-they insisted-became "real" to them in a way in which no previous research essay had been able to achieve.

Another aspect of the project that was universally commented on was the opportunity to share their research and creativity with a broader audience, not just with one reader (the instructor), as is the case with a research paper. As Jennie Long, one of first group of students noted, "by learning to use online visualization platforms, such as StoryMapJS and Gigapixel.com, we were able to make our content more accessible to a broader public.... This exploratory way of learning makes my work more accessible-for the first time, I've been able to show my friends and family what I'm learning and working on in my studies at uOttawa” (2).

For the course instructor and the librarians, yet another surprise was students' sustained engagement. Although each group project was designed to take up 30 hours of students' time, in each case it ate up considerably more; in at least two cases (according to students' own estimates), over 100 hours. They attributed some of the extra hours to the learning of new platforms and programs, to solving technical challenges, and to correcting errors. But the overwhelming number of hours was, astonishingly, freely given over to archival work above and beyond the requirements of the project. Not only did students appear not to resent the extra time spent but they enthusiastically revelled in its challenges. They were discovering Shakespeare for themselves. In carrying out this research, they learned about Canada's history-their history, their selvesand the many roles that Shakespeare played in it. As their final reports indicated, they claimed that they would do it all over again. This claim was subsequently borne out when some of the students did indeed take up similar projects in the next few years. 
Enthusiastic about expanding their skills in a digital environment, they came out of this project with a passion for working with archives which some have already taken further, to the graduate level. The energizing factor of the project thus seems to have been not the digital but rather the reciprocal relationship between analogue and digital. We may conceive of this connection as a Moebius strip: the archival documents they discovered spurred on their research which, in turn made them think creatively (How to transfer this information into a visual form? How to create a narrative arc from these documents?); and then technologically (What platforms, what data management systems would be needed to make this work?). The opportunity and ability to reach a wider audience- one which could both appreciate and also critique their work-added further stimulus to ambition.

The success experienced with this first cohort of students was inspiring and resulted in the decision to carry on the project for another four years. It also led to the initiation of a new collaborative research project, Shakespeare in Canada: A Cultural Map, an online interactive cultural map and timeline of Shakespeare's presence in Canada which will eventually be made available in an open-access format to researchers around the globe. For the course instructor, it opened up the pleasures of working and teaching in a new way. It also opened up a new field of inquiry — Shakespeare in the Arctic — the result of the students' discovery in Library and Archives Canada of an 1853 playbill of The Taming of the Shrew onboard the HMS Resolute searching for the lost Franklin expedition.

\section{Challenges and Obstacles}

Despite its many successes and pleasures, the pilot project did not come without challenges. The obstacles encountered provided an opportunity in the following years to refine the pedagogical approach and improve the students' learning experience. As already suggested above, communication presented one of the more significant challenges. Because students required more support than was expected, mandatory weekly meetings were introduced to provide a venue to give and receive feedback on their projects. The weekly meetings held outside of class time were well attended but scheduling of many different timetables proved to be problematic. In a further iteration, to alleviate such scheduling issues, weekly meetings were replaced by the addition of workshops and troubleshooting sessions during class time. In 2019, Discord, a free, open online voice- and text- chat application that enabled real time communication between the students, the instructor, and the library team was also added. Discord allowed participants to communicate with each other and share links, images and text files. It is accessed through a web browser or by downloading the desktop or 
mobile application. The class Discord community was also used as the main course communication method by the instructor. Despite a slow start, students eventually embraced this mode of communication. Its possibility of rapid feedback was particularly helpful in responding to questions about cataloguing and software troubleshooting.

Another significant challenge was student time management of the projects. To underscore the importance of responsibility and accountability as an essential part of any collaborative endeavour, students in the second iteration of the project were required to submit a detailed work plan with deadlines and deliverables. This approach produced mixed results and highlighted the difficulty students experienced when tasked with scaling their projects. The work plan was subsequently removed as a requirement and replaced by more restrictive assignment guidelines. These included the simplification of metadata requirements (cataloguing now occurring directly in Omeka using a simple Dublin Core schema); fewer and more pointed project themes and fewer choices of archival collections; and a restricted number of plugins. The new prescriptive project parameters allowed students to experiment with archival material and digital tools, and stretch their creativity while reducing the anxiety they had experienced, which was associated with a steep learning curve and with the logistical components of the project.

The librarians, in consultation with the course instructor, produced an extensive, detailed online manual for the students, guiding them every step of the way in the project, specifying dates and deadlines; contact numbers and people; providing cataloguing information and numerous examples; correct citation format, and so forth. Ironically and unexpectedly, most students kept forgetting to consult the online guide. As a result, in the last two iterations of the project, a printed manual was provided which the students did indeed consult.

In the early iterations of the project, librarians and research assistants were able to take the students to visit the archives (the teaching and administrative schedules of the course instructor prevented her from doing so). In the last three iterations, however, the archival-digital component was thoroughly embedded in well-spaced out three-hour seminars. This opened up the opportunity for the instructor to oversee and participate in every aspect their projects: from the classroom, where they studied theories of adaptations, translation, and archival research; to the archives; and the workshops, where they were assisted in researching their topics and shaping the narrative of their exhibits.

A final challenge should be mentioned. The organizational effort of introducing an archival-digital component into course work is time-consuming. The collaborative team of archivists, librarians, and media specialists must be set up well in advance; project themes, articulated; fonds pre-ordered; workshops scheduled; a step-by-step manual, written; and, of course, the material for 
theoretical, historical, and textual study in the classroom must be prepared. Yet, as has been suggested above, the massive preparation required was amply compensated by the response of the students. Here are some of the most recent reflections about the project from students in a graduate seminar, Shakespeare in Canada:

Shakespeare is a way to define who we are and where we are going. This vivacity that Shakespeare has in adaptation has really stood out to me this semester. I think that this is in part because of this project and witnessing firsthand the ways that every theatre production opens up to so many personal interpretations. This is true of the project itself too. ...To me, this collaborative effort feels very true to the spirit of theatre as well, as the nature of this project reflects the infinite versions of Shakespeare born out of so many individual factors, wills, and circumstances.... This semester has really driven home for me a personal, not universal Shakespeare.... This course and this project for me, have been steps in discovering my own Shakespeare, and I have been reminded throughout the semester of why finding that relationship is so meaningful. Thank you to everyone involved for this opportunity. I have really enjoyed and appreciated it. (Evonne Downer)

One of my favourite parts of working on this project was the element that was necessarily collaborative. Any digital humanities project is inherently interdisciplinary, meaning that people undertaking such work will have the opportunity to learn new skills and work with people that they might not encounter in the normal research. (Kaitlyn Arsenault)

This project was a big learning curve in many ways, as I had to adjust my expectations of what was normally expected of me in a literature class to something entirely new. Without the standard critical essays as assignments, I was able to "stretch" different scholarly "muscles" and learn how to work within a new context of theatre and digital humanities. I was also excited to learn about archival work and to be able to visit the archives both at the University of Ottawa and the National Arts Centre. This class has now made me strongly consider a future career in information technology or as an archivist and I am excited to learn more about the fields. Working on digital platforms such as Omeka and StoryMap was also an adjustment, but it was interesting to learn the technology and create something for the public eye. The use of this technology also allowed for us to work with our archival sources and research in creative and interpretive ways, which resulted in an eye-catching and informative visual project. This project and class ultimately demonstrated that there are thousands of possibilities and opportunities for scholarship when working with Shakespeare, especially in today's modern technological age. (Kristyna Frenken-Francis) $^{9}$

9 Students cited in this article have given permission to have their comments used in this article. 


\section{Conclusion}

The sustained enthusiasm of the participating students demonstrates the visual and tactile appeal of teaching with collections. As digital humanities programs continue to gain momentum both at the undergraduate and graduate levels, initiatives such as the Shakespeare in Canada project will become more common in humanities classrooms. As such, it is essential to continue to seek out and develop new and unexpected collaboration between faculty, libraries, archival institutions, and museums. These partnerships offer students access to a wealth of artefact collections and create innovative learning opportunities that emphasize personal connections with the humanities.

A concluding but, by no means, final note on this topic: In the institutional rush toward embracing the digital and transforming our humanities programs, we might wish to rethink some of our assumptions about what students need and from what they might derive most satisfaction. The digital world does open up various doors; it breaks down barriers between instructors, archivists, librarians, and students. It enriches the students' experience of university. It challenges them to talk to and seek help both from each other and from others. Yet, as the results of this pilot project and its subsequent iterations have also suggested, the old "technology" - archives, museums, libraries—can be not only the impetus for creative and historical awakenings but also the rich medium with which students can still fall in love.

\section{WORKS CITED}

Arsenault, Kaitlyn. "Reflections on the Shakespeare and Canada DH Project." End-ofterm reflective paper for ENG 7325 Shakespeare and Canada. Winter 2019. Instructor: I. Makaryk.

Brisset, Annie. "Shakespeare, A Late Bloomer on the Quebec Stage." In Shakespeare and Canada: 'remembrance of ourselves.' Ed. Irena R. Makaryk and Kathryn Prince. University of Ottawa Press, 2017. 127-56.

Colarusso, Dana M. "Rhyme and Reason: Shakespeare's Exceptional Status and Role in Canadian Education.” In Makaryk and Prince. 215-40.

Downer, Evonne. "Reflections on the Shakespeare and Canada DH Project." End-ofterm reflective paper for ENG 7325 Shakespeare and Canada. Winter 2019. Instructor: I. Makaryk.

Engler, Balz. "The Classic as Public Symbol.” REAL: Yearbook of Research in English and American Literature (Tübingen: Gunter Narr, 1988-89) 6 (1988-89): 217-36.

Frenken-Francis, Kristyna. "Reflections on the Shakespeare and Canada DH Project." End-of-term reflective paper for ENG 7325 Shakespeare and Canada. Winter 2019. Instructor: I. Makaryk. 
Giannetti, Francesca. "Against the Grain: Reading for the Challenges of Collaborative Digital Humanities Pedagogy.” College \& Undergraduate Libraries 24.2-4 (Apr. 2017): 257-269. Library, Information Science \& Technology Abstracts. doi: 10.1080/10691316.2017.1340217.

Griffin, Melanie and Tomaro I. Taylor. "Shifting Expectations: Revisiting Core Concepts of Academic Librarianship in Undergraduate Classes with a Digital Humanities Focus.” College \& Undergraduate Libraries 24.2-4 (2017): 452-466. Library, Information Science \& Technology Abstracts. doi: 10.1080/ 10691316.2017.1325346. Accessed 24 June 2019.

Long, Jennie. "Reflections on the CSL Project." End-of-term reflective paper for ENG 3133B Elizabethan Shakespeare, Winter Term 2016. Instructor: I. Makaryk.

Mackenzie, Sarah. "Performing 'Indigenous Shakespeare' in Canada: The Tempest and The Death of a Chief." In Makaryk and Prince. 111-25.

Makaryk, Irena R. "Introduction: Shakespeare in Canada: 'a world elsewhere.”' In Shakespeare in Canada: 'a world elsewhere.' Ed. Diana Brydon and Irena R. Makaryk. Toronto: University of Toronto Press, 2002. 3-41.

Makaryk, Irena R. and Kathryn Prince, eds. Shakespeare and Canada: 'remembrance of ourselves.' University of Ottawa Press, 2017.

VanderBerg, Robert. "Converging Libraries, Archives and Museums: overcoming distinctions, but for what gain?” Archives and Manuscripts 40.3 (November 2012): 136-146. 